BULLETIN Bulletin hispanique

HISPANIQUE Université Michel de Montaigne Bordeaux

120-2 | 2018

Varia

\title{
Melpómene con Talía. Formas de la tragicomedia en el teatro español anterior a la Comedia nueva
}

Melpomène avec Thalie. La tragicomédie dans le théâtre espagnol antérieur à la Comedia nueva

Melpomeni with Thalia. The tragicomedy in the Spanish plays previous to the "Comedia Nueva"

David Mañero Lozano

\section{OpenEdition}

\section{Journals}

Edición electrónica

URL: https://journals.openedition.org/bulletinhispanique/7038

DOI: 10.4000/bulletinhispanique.7038

ISSN: 1775-3821

\section{Editor}

Presses universitaires de Bordeaux

\section{Edición impresa}

Fecha de publicación: 10 diciembre 2018

Paginación: 581-598

ISBN: 979-10-300-0337-6

ISSN: 0007-4640

Referencia electrónica

David Mañero Lozano, «Melpómene con Talía. Formas de la tragicomedia en el teatro español anterior a la Comedia nueva», Bulletin hispanique [En línea], 120-2 | 2018, Publicado el 02 enero 2022, consultado el 08 enero 2022. URL: http://journals.openedition.org/bulletinhispanique/7038 ; DOI: https://doi.org/10.4000/bulletinhispanique.7038 


\title{
Melpómene con Talía. Formas de la tragicomedia en el teatro español anterior a la Comedia nueva ${ }^{1}$
}

\author{
David Mañero Lozano \\ Universidad de Jaén - España
}

Melpomène avec Thalie. La tragicomédie dans le théâtre espagnol antérieur à la Comedia nueva

Ce travail présente une approche des formes que prend la tragicomédie dans le théâtre espagnol du XVI ${ }^{\mathrm{e}}$ siècle, ainsi que de ses relations avec la tradition européenne.

Mots-clés : tragicomédie, théâtre espagnol du Siècle d'Or, Comedia nueva.

Este trabajo ofrece una aproximación a los desarrollos de la tragicomedia en el teatro español del siglo xvi, así como sus relaciones con la tradición europea.

Palabras clave: tragicomedia, teatro español del Siglo de Oro, Comedia nueva.

Melpomeni with Thalia. The tragicomedy in the Spanish plays previous to the "Comedia Nueva"

This paper offers an approach to the development of the tragicomedy in the Spanish theater of the $16^{\text {th }}$ century, as well as its relationships with the European tradition.

Keywords: tragicomedy, Spanish theatre in the Golden Century, Comedia Nueva.

1. Este artículo se enmarca dentro del proyecto de $\mathrm{I}+\mathrm{D}$ del Ministerio de Economía y Competitividad titulado «La obra dramática de Agustín Moreto. Edición de sus comedias IV. Las comedias escritas en colaboración» (Referencia: FFI2014-58570-P). Agradezco las útiles observaciones de Antonio Carreira y de David González Ramírez. 


\section{ANTECEDENTES Y PLANTEAMIENTO}

Han transcurrido más de cuatro décadas desde que Barrick (1973: 52) señalara la necesidad de un estudio en el que se abordase el concepto de tragicomedia y se profundizase en sus posibles manifestaciones en la literatura española. Desde entonces, contamos con un repertorio más amplio de tentativas críticas, si bien estas se centran en el análisis de autores o de manifestaciones dramáticas concretas ${ }^{2}$.

En el presente estudio me propongo indagar sobre las corrientes teatrales en las que los autores espańoles ensayaron la mezcla de elementos de la comedia y la tragedia. Consciente de la imposibilidad de abarcar un panorama exhaustivo, he valorado, en primer lugar, las adaptaciones al español de la comedia latina, que aportaron interesantes acercamientos a la tragicomedia. Por otra parte, debe tenerse en cuenta el teatro renacentista de influencia clásica, en particular por las tragicomedias celestinescas y las piezas de Torres Naharro. La mezcla de géneros es apreciable, también, en Encina y en las denominadas farsas «a manera de tragedias». La conjunción de rasgos genéricos cristalizó, asimismo, en numerosas piezas escritas en Europa y en corrientes como el "Terencio cristiano", que dejaron su impronta en los autores españoles, bien de modo directo o mediante traducciones. Se trata de tradiciones literarias que han recibido la atención de la crítica, pero hasta el momento carecemos de un estudio de conjunto sobre las expresiones de la tragicomedia previas al surgimiento de la comedia nueva.

Según me propongo argumentar, la tragicomedia no puede definirse como un género con unos rasgos inherentes a todas aquellas piezas en las que se hibridaron rasgos cómicos y trágicos. Antes bien, el concepto designa tradiciones dramáticas de naturaleza innovadora que evolucionaron por diferentes caminos durante el s. XVI y, en algunos casos, confluyeron dando lugar a aportaciones difícilmente tipificables.

\section{El MOdELO ClÁSICO. ORÍGENES DE LA TRAGICOMEdia}

Sabemos que Plauto fue el creador, si no del género, sí del concepto tragicocomoedia. No faltan precedentes griegos, pero fue el cómico latino quien formuló explícitamente la existencia de un género mixto. Según expone

2. Según concluye Egido (1998: 100), al término de su valioso acercamiento a las «imágenes de la mezcla tragicómica»: "El asunto es complejo y conlleva numerosas ramificaciones que abarcan campos de análisis diversos que convendría explorar detenidamente». En cuanto a los problemas teóricos suscitados por la mezcla de géneros y las ideas de los preceptistas, en lo que no puedo detenerme en estas páginas, remito también a Newels (1974), Cascardi (19761977), Álvarez Sellers (1996), Blanco (1998), Trambaioli (2010) y Arellano (2011), entre otros dedicados a la fórmula lopesca, de la que tampoco me ocupo por limitaciones evidentes de espacio. 
Mercurio en el prólogo del Anfitrión, esta pieza se caracteriza por una variedad genérica emanada de la disparidad social de sus personajes (Plauto, 1993: 81).

Entre los acercamientos a la comedia latina en español, destaca la original adaptación del Anfitrión realizada por Pérez de Oliva hacia 1525. Existen motivos para pensar, con Peale, que Pérez de Oliva "concibió sus tres obras de teatro como [...] el primer manual de retórica en lengua castellana» (Pérez de Oliva, 1976: xxxIV-Xxxv).

Los presupuestos teóricos se exponen en la nota previa a la traducción de Plauto. En primer lugar, se considera a Terencio como modelo de elocuencia (Pérez de Oliva 1976: 4). En cuanto a su visión del género cómico, esta se aparta de la ortodoxia aristotélica. Reparemos en las siguientes declaraciones sobre el decoro, que se anticipan al Arte nuevo de Lope:

[...] el estilo de dezir en comedia es tan diverso como los movimientos de los hombres. A vezes va tibio, y a vezes con hervor; unas con odio, y otras con amor; grave algunas vezes, y otras veces gracioso; unas veces como historia, otras como razonamiento, y otras vezes es habla familiar (Pérez de Oliva, 1976: 4).

Tales afirmaciones no quedan en una mera declaración de intenciones, dado que el texto refleja este variado repertorio de modalidades expresivas. Sin salir de las tres primeras escenas, Peale, para quien la adaptación de Oliva es «una antología del decoro lingüístico» (Pérez de Oliva 1976: xi), ejemplifica los registros adoptados por los personajes en función de su condición social y de las situaciones dramáticas. De este modo, a lo largo del siglo XvI, las traducciones y adaptaciones de obras latinas contribuyeron a ampliar las posibilidades expresivas de la comedia, más allá de los límites establecidos por la preceptiva.

\section{TRAgicomedias CELESTINESCAS}

No por azar, es Fernando de Rojas, paradigma de la inquietud por aclimatar en Espańa la comedia latina, quien emplea por vez primera en español el término tragicomedia ${ }^{3}$, con el que se refiere al contraste entre el "placer» del comienzo y la "tristeza» del desenlace (Rojas 2000: 20-21).

Además de la coincidencia con Plauto en el empleo de un rótulo novedoso, la intervención de personajes desiguales en la Celestina coincide con el drama plautino, aunque la influencia del cómico latino no ha sido valorada uniformemente (Rojas 2000: 512-513). De cualquier modo, siervos y nobles poseen una identidad social bien definida y desempeñan funciones relevantes

3. Con anterioridad a Rojas, cabe mencionar el testimonio de Caroli Verardi, en el prefacio al Fernandus Servatus (Roma 1493) de Marcelino Verardo de Cesena, en el que, por vez primera en el Renacimiento, se hace eco del término plautino: «Potest enim haec nostra: ut Amphitruonem suum Plautus appelat: Tragicocomoedia nuncupari: quod personarum dignitas \& Regiae maiestatis impia illa uilotatio ad Tragoediam; iucundus uero exitus rerum ad Comoediam pertinere uideantur» (Cabranes-Grant 1998: 58-59). No parece que el Fernandus Servatus dejara huella en España, aunque sí en Alemania (Herrick 1955: 6). 
en ambos dramaturgos. En opinión de Newels (1974: 127), quien apela al testimonio de Luis Vives, el final trágico de la Celestina implica la supeditación de las convenciones cómicas a la ejemplaridad moral impuesta a raíz de la creación de un «Terencio cristiano». Aceptemos o no esta interpretación, la propuesta de Rojas responde a una inquietud manifestada en otros países europeos desde comienzos del s. XvI.

La fórmula dramática de Rojas se mantuvo vigente en la tradición celestinesca, en la que se automatizó el empleo del título tragicomedia. Es el caso de las versificaciones de Urrea (1513) y Sedeño (1540). La Tercera parte de la tragicomedia de Celestina, de Gaspar Gómez de Toledo (Medina del Campo 1536; y Toledo 1539), recurrió a la misma denominación. Se asume, por tanto, el modelo inaugural, "aun cuando en la Tercera Celestina la tragedia no alcance a los enamorados» (Esteban Martín 1987: 4), y a pesar de que Gómez de Toledo no retome la obra de Rojas, sino la Segunda Celestina de Silva. Más allá de la mezcla de géneros que presupone el título, la acción se nutre de elementos cómicos y trágicos ya presentes en la Segunda Celestina de Silva. Ejemplo de esto son Felides y Polandria, cuya expresión de las convenciones cortesanas amplía el abanico de estilos desplegado por los rufianes o la negra Boruga. Ya en la Segunda Celestina, el estilo artificioso de los protagonistas y de Poncia se opone al habla de germanías, o de los pastores rústicos y de los negros.

Transcurridos tres años, la demanda de Celestinas quedó satisfecha con la Tragicomedia de Lisandro y Roselia..., de 1542. Navarro Durán destaca la variedad de registros estilísticos, rasgo en el que, a su juicio, se cifra «la forma de creación artística: [...] perfeccionando uno de los caminos emprendidos en esa imitación de lo real: reproducir tipos distintos de hablas» (Muñón 2009: 68). La idea se refrenda en el «Prólogo al discreto lector», basado en las observaciones de Horacio sobre el decoro literario.

En 1547 se imprime otra de las obras emparentadas con el modelo de Rojas, la Tragedia Policiana, cuyo subtítulo reza: «En la cual se tractan los muy desdichados amores de Policiano y Philomena. Executados por industria de la diabólica vieja Claudina, madre de Pármeno y maestra de Celestina». Nuevamente, se da un desenlace trágico a una trama en la que participan personajes cómicos. Por otro lado, desde las palabras preliminares, se alude a «algún color ridículo», "palabras graciosas y apazibles donayres», que se alternan con la «erudición», además de «los sobresaltos, las angustias, las affrentas, los sinsabores» (Fernández 1992: 101-2) y otras circunstancias opuestas a la comedia.

Ya distante de estos títulos, contamos con una quinta y tardía continuación de la Celestina (ca. 1564), descubierta en 1988 por Arata, quien «de forma provisional» (46) la tituló Tragicomedia de Polidoro y Casandrina. La cautela mostrada al escoger el rótulo está justificada, dado que la obra parodia los elementos celestinescos para dejar paso a nuevos intereses literarios e ideológicos, que desvirtúan la dimensión trágica de las obras precedentes (Vian Herrero 2003). No en balde, habían transcurrido dos décadas desde que se publicase la última de las Celestinas, lo que quizá explique el desapego hacia el modelo. 
Para Juan del Encina, era importante difundir la «copilación de todas sus obras» (1991: 97). No se trataba únicamente de fijar un texto fidedigno y de legitimar la exacta composición de su corpus literario, sino que el autor se ocupó de esta empresa "porque no pensasen que toda su obra era pastoril, según algunos dezían, mas antes conociessen que a más se estendía su saber» (ibid.). Esta voluntad por superar la materia de pastores se hace patente desde el Arte de poesía castellana, dispuesta como pórtico a su Cancionero de 1496. Paralelamente, la evolución de sus églogas refleja una búsqueda constante de registros y una absorción de influencias literarias que dio sus frutos más logrados hacia 1513, en la Égloga de Plácida y Vitoriano.

A diferencia del resto de las composiciones de Encina, este último ensayo dramático asume desde el comienzo las convenciones de la comedia latina, al encomendar la introducción de la pieza a una figura que expone el argumento y presenta a los personajes. Además, a imitación de Plauto, Encina aprovecha el prólogo para reflexionar sobre la factura genérica de su obra. El pastor encargado de la presentación, Gil Cestero, tipifica la composición como "comedia» que acaba "con gran placer y consuelo» (1991: 292). Ahora bien, este desenlace solo es posible gracias a la intervención de Venus, quien evita el suicidio de Vitoriano e invoca a Mercurio para que resucite a Plácida. Se reconduce así hacia la comedia lo que de otro modo habría desembocado en tragedia. Por un lado, se recurre a un final feliz, pero por otro advertimos que la intervención de dioses y la condición cortesana de los personajes, prácticamente despojados de los hábitos pastoriles de las anteriores églogas, están asociados a la tragedia. Estamos ante un tempranísimo ejercicio de asimilación de distintas tradiciones, en el que destacan correspondencias con la síntesis genérica de la comedia latina, que alentó asimismo la literatura pastoril italiana de finales del s. $\mathrm{XV}$ y comienzos del $\mathrm{XVI}^{4}$.

Poco se puede aportar al estudio de la «segunda producción dramática» de Encina (1991: 67-80), aunque convendría revisar su influencia en algunas obras poco atendidas, no sin antes mencionar las Farsas y Églogas de Lucas Fernández, en las que se ensaya una interesante mezcla de rasgos genéricos. Es reseñable la vacilación de los títulos empleados por este autor, que en ocasiones formula una doble denominación (así Égloga o farsa y Auto o farsa). Este es un aspecto destacado por Newels, quien sugiere que el término «églogas» tal vez designe solo el empleo del metro y la forma dialogada. La misma vaguedad denotativa afecta a «auto» $\mathrm{o}$ "farsa», etiquetas que poco a poco dejaron paso a la voz "comedia» (Newels 1974: 132-4), que subsumió influencias diversas, más allá de las resonancias clásicas heredadas.

La mezcla de elementos de la tragedia y la farsa (entiéndase aquí 'pieza cómica breve') cuenta con exponentes tempranos, como la doblemente titulada

4. En particular, es de notar el desenlace trágico de algunas de las églogas compuestas en Italia. 
Farsa de Lucrecia. Tragedia de la castidad de Lucrecia, de Juan Pastor, datada hacia 1530. El desarrollo de la trama, el desenlace trágico (con el suicidio de Lucrecia y la venganza de sangre) y la condición aristocrática de los personajes, que emplean un estilo elevado, se ajustan a la concepción clásica de la tragedia. Sin embargo, los componentes de farsa, introducidos por dos de los personajes (el negro y en mayor medida el bobo), aportan cierta distensión cómica, sin excesivas repercusiones sobre la acción. De cualquier modo, el desarrollo trágico se altera mediante el recurso al estilo rústico y las situaciones burlescas 5 .

Otra de las obras que alude en su propio título a la mezcla de géneros es la Farça a manera de tragedia (Valencia 1537), que se aleja de la imitación clasicista practicada por Juan Pastor. Basta un simple vistazo al elenco de personajes, conformado por un reducido grupo de pastores y labradores, para encuadrar la obra dentro de las convenciones cómicas. Sin embargo, según se declara en el prólogo, puesto en boca de un pastor, el desenlace trágico obliga a una categorización genérica diferente de la farsa: «Y aquesta farça merece, / pues que pena y no remedia, / que la llamemos tragedia / porqu'en dos muertes fenece» (Rennert 1914: 15, vv. 82-5).

No hay duda de la deuda contraída con la Égloga de Plácida y Vitoriano de Encina. Además de la concepción dramática y la ambientación pastoril, las dos obras comparten rasgos encinianos tan definitorios como el uso del sayagués y el desenlace en suicidio, al que también se recurre en la Égloga de Fileno, Zambardo y Cardonio.

\section{Comedias con elementos trágicos. Torres Naharro y Gil Vicente}

La concepción clásica del decoro literario, en la que se sustentó durante siglos la distinción entre comedia y tragedia, se difundió entre los primeros dramaturgos españoles gracias a aportaciones como el Arte de la poesía castellana (1496) de Encina. Sin embargo, el conocimiento del legado clásico no impidió que autores como Torres Naharro introdujesen nuevos planteamientos que modelaron y extendieron los rasgos de la tragicomedia. En el «Prohemio» que acompaña a la Propalladia (1517), se recomienda «qu’el siervo no diga ni haga actos del seńor et e converso y el lugar triste entristecello, y el alegre alegrallo» (Torres Naharro 2013: 971).

5. El planteamiento de la Farsa de Lucrecia o Tragedia de la castidad de Lucrecia de Juan Pastor se asemeja a la Tragicomedia llamada Filomena, incluida por Timoneda en la Turiana (1564), que se describe en su portada como «muy apacible y graciosa». A esta valoración se suman los acontecimientos trágicos, además de la temática histórica («de cierta historia sacada», indica el v. 9), que justifican el título empleado (Mérimée 1913: 178-9). Igualmente significativo es el contraste entre las expresiones rústicas y el tono elevado de los distintos tipos de personajes.

6. Rodrigo Mancho (1984) subraya tanto la impronta de Encina y de Torres Naharro como la de la Celestina. En su opinión, «la Farça a manera de tragedia es una premonición de lo que constituirá el drama nacional barroco, la mezcla de asuntos dramáticos, la tragicomedia lopesca» (Rodrigo Mancho, 1984: 226). 
El extremeño se basó en los Prenotamenta Terentii (Torres Naharro 1951: III, 25-26) del belga Josse Bade de Asche, publicados hacia 1502 como introducción a su edición de las obras de Terencio. Pero reparemos en la precisión et e converso ['y a la inversa'], con la que se admite la intervención de personajes elevados en la comedia, a condición de que adopten un registro estilístico y una conducta que los diferencien del «siervo». Unido a esto, la definición de comedia asumida, que se distancia de «los antiguos»-«Quiero ora decir yo mi parecer»-, prescinde de la restricción aristotélica de imitar a «hombres inferiores»: «Y digo ansí que comedia no es otra cosa sino un artificio ingenioso de notables y finalmente alegres acontecimientos por personas disputado» (Torres Naharro 2013: 971). El dramaturgo alude simplemente a "personas», sin calificativos, planteamiento consecuente con la variedad de personajes de sus comedias, en las que se contempla la proverbial atribución de acontecimientos «notables» a los sujetos elevados.

Por otro lado, aunque el desenlace de la comedia depare sucesos «alegres», determinadas piezas incluyen elementos trágicos, y algunos personajes manifiestan inquietudes propias de los nobles, como el problema del honor. Esto se corresponde con lo que El Pinciano tipifica como tragedias «mezcladas con la cómica», en las que los «terrores y espantos y calamidades en el medio y fin de la acción» desembocan en un «deleyte cómico y fin próspero» (López Pinciano: II, 345).

Un ejemplo de la mezcla de recursos genéricos es la comedia Serafina. La crítica ha destacado la factura cómica de personajes como el caballero Floristán. Pero, al margen de la inconsistencia moral y de la ironía con la que se perfila esta figura, el conflicto recreado en pasajes como el de la confesión de Floristán, acuciado por la conveniencia de asesinar a su esposa, nos envuelve por momentos en la esfera trágica. Algo similar puede apuntarse de los impulsos suicidas de la princesa Felicina en la comedia Aquilana. La escena en cuestión contiene evidentes contrapuntos cómicos, que no pasaron inadvertidos para lectores como Juan de Valdés, quien afirma que Torres Naharro "peca algo en las comedias no guardando bien el decoro de las personas», dado que «se pierde quando quiere escrevir lo que passa entre gente noble y principal, lo qual se vee largamente en la comedia Aquilana» (Valdés 2010: 246-7). Sin embargo, antes de que se introduzcan los mencionados contrastes cómicos, en la quinta jornada, Felicina declama un primer parlamento con una altura trágica incuestionable, en el que se hace un significativo guiño a la resolución final de Melibea.

Ya en piezas tempranas, como la comedia Trophea, aún anclada en las tradiciones dramáticas del $s$. Xv, se alternan los parlamentos de la Fama, Tolomeo o el intérprete de los veinte reyes paganos con las escenas protagonizadas por Caxcoluzio, Juan Tomillo, Mingo Oveja o Gil Bragado. Por otra parte, la Celestina influye visiblemente en este dramaturgo. Más allá de la imitación de escenas concretas o de los personajes de Rojas, se adopta un esquema compositivo posiblemente inspirado en la Tragicomedia. Me refiero 
al desarrollo de una intriga secundaria en la que participan los criados y otros personajes humildes, en paralelo a la acción principal protagonizada por los nobles, según es patente en Serafina, Calamita e Himenea. ${ }^{7}$. Aunque algunos de los caracteres y situaciones proceden del teatro latino e italiano, es poco probable que al autor le pasaran inadvertidas las intrigas secundarias surgidas en torno al mundo prostibulario de la Celestina.

Estas circunstancias no logran contrarrestar el predominio del tono burlesco. Del mismo modo, no puede afirmarse que la intervención de personajes de alta condición se proponga conmover al espectador. En la mencionada escena de Felicina de la Comedia Aquilana, por ejemplo, el humorismo se basa en la ruptura de las expectativas generadas por situaciones trágicas. Así, en el parlamento inicial de la jornada quinta, el personaje crea una atmósfera de tragedia, sin que interfieran elementos disonantes. Sin embargo, la emotividad de la escena se interrumpe justo en este momento, al entrar Dileta, cuyo registro léxico contrasta ridículamente con el de Felicina: «Mi señora, / por allí llevan agora / tu bien todo engarrafado». Poco después, la princesa continúa deliberando sobre el modo de quitarse la vida, si bien esta vez se plantea una imagen sin lirismo, que imprime un sesgo grotesco a la situación (Torres Naharro 2013: 909). Finalmente, la comicidad impregna toda la escena, al frustrarse el suicidio debido a la torpeza de Felicina para anudarse la soga al cuello. Esta desarticulación burlesca de las escenas trágicas contribuyó a flexibilizar las relaciones entre géneros dramáticos, como parte del dilatado y complejo proceso que dio lugar a la comedia nueva.

En otro orden de cosas, pese a adoptar un enfoque satírico con el que se distancia de los asuntos referidos, las comedias «a noticia» de Torres Naharro se ocupan de la "cosa nota y vista en realidad de verdad", de modo que la comedia se adentra en un terreno que la tradición clásica reservaba a la tragedia (Newels 1974: 130). A este propósito, el dramaturgo se hace eco de la definición de comedia atribuida a Cicerón por los comentadores de Terencio: «imitatio vite, speculum consuetudinis, imago veritatis» (Torres Naharro 2013: 968 y n. 20).

Otro de los dramaturgos que experimentaron tempranamente la mezcla de géneros es Gil Vicente. No fue este autor, sin embargo, quien asignó el marbete genérico a su Tragicomedia de Don Duardos, compuesta hacia 1522, y a la Tragicomedia de Amadís de Gaula, dado que el título de las dos piezas fue responsabilidad de los editores encargados de la Compilaçam en 1562 y 1586. Así, se optó por emplear esta etiqueta en los índices ${ }^{8}$, que contrasta con el título «auto» estampado en el encabezamiento de ambas obras en la edición de 1586, y se aparta también de las categorías empleadas por el autor, quien únicamente se refiere a "comedias, farças y moralidades» (Vicente 1996: 473, n. 187a). Por otra parte, la denominación «tragicomedia» había sido utilizada

7. En la Himenea, que a juicio del autor «no es comedia de risadas» (Torres Naharro, 2013: 542), las diferencias sociales entre nobles y criados quedan patentes desde la «tabla de personajes».

8. Al publicarse en 1562 las obras completas del autor, al cuidado de sus hijos, se establece una división en cinco libros, que asigna al tercero el título Tragicomédias. 
en 1539, en la anónima adaptación de las Barcas de Gil Vicente, publicada en Burgos con el título Tragicomedia alegórica del paraíso y del infierno". Ninguna de estas decisiones editoriales parece atribuible a la voluntad del autor, pero, si atendemos al plano de la recepción, la insistente vinculación de algunas de sus obras con la tragicomedia nos conduce a interpretarla como tal.

Reparemos, por otro lado, en la caracterización social de los personajes de las tragicomedias sobre el príncipe don Duardos y el caballero Amadís. Atrás quedaron pastores, porquerizos y otros caracteres heredados de la tradición medieval, para dar paso a «altas figuras [...] con tan dulce retórica y escogido estilo» (Vicente 1996: 474, n. 187a), según subraya el autor en las palabras dedicadas al Don Duardos dentro de la Compilaçam de 1586. No estamos, con todo, ante personajes constreńidos de principio a fin a las convenciones retóricas. Por virtud de un recurso que la comedia nueva convertirá en rutinario, el protagonista decide "mudar la vida / y el nombre y el estado / y el vestido", hasta quedar "de príncipe hecho villano" (Vicente, 1996: 205). Mediante este procedimiento, se resienten los criterios que cimentaban la separación de géneros. El desajuste producido entre la apariencia humilde del personaje y su condición elevada es puesto de manifiesto por Flérida, quien evidencia la falta de decoro con la que se expresa Don Duardos al disfrazarse por primera vez de hortelano (Vicente, 1996: 215).

Por lo demás, el conflicto dramático plantea la dialéctica entre el poder igualador del amor y las imposiciones sociales derivadas del decoro. Pero, al margen de estos juegos de suplantación de identidades, tanto en la Tragicomedia de Don Duardos como en la Tragicomedia de Amadís de Gaula, se da otra circunstancia que implica la mixtura de géneros. La condición elevada de los personajes se conjuga con una trama cómica, resuelta en ambas piezas con un final de comedia. Estamos ante un ensayo dramático afín a los presupuestos teóricos de Torres Naharro, quien desarrolla «notables y finalmente alegres acontecimientos». En cualquier caso, tanto el aprovechamiento de las fuentes novelescas como la alteración de la identidad social de los personajes suponen una novedosa conjunción de escenas cómicas y «notables» con las que Gil Vicente experimentó el potencial creativo de la tragicomedia.

\section{Tragicomedia humanística}

Dentro del teatro neolatino humanístico y escolar, la tragicocomoedia cedió el testigo a ejercicios literarios con influencias cultas y populares (García Soriano 1945: 41). Al igual que en la Celestina, intervienen en estas obras personajes de diferentes clases sociales.

9. Según conjetura Barrick: «The author's reason for calling the work a tragicomedy is not readily apparent. Possibly because the ending is felicitous for some of the characters but not for others he conceived of the work as the type of mixture recognized by Rojas in the Celestina» (1973: 55). 
Una de las primeras piezas con las que contamos es la Nova tragicomoedia Gastrimargus de Jaime Romañá ${ }^{10}$, que a juicio de Alonso Asenjo y Molina Sánchez (2006: IV-XIII) se compuso y representó en Valencia hacia 1530. Tras recalcar su «nueva perspectiva cómica», el prólogo de esta obra describe la tradición dramática a la que se adscribe: «[...] penetrando en el escabroso terreno de la tragedia y de las dolorosas tribulaciones, mezcla el placer con la tristeza. Así puede llamársele 'tragicomedia', el mismo género poético al que pertenecen Acolasto, Josefina y Celestina» (Alonso Asenjo / Molina Sánchez 2006: 68-9). Aunque el género celestinesco ya estaba consolidado, el autor se defiende ante posibles críticas, para lo cual echa mano de las interpelaciones al auditorio propias de la comedia clásica: «¿Qué mascullas tú, deslenguado, que no puede decirse que una cosa seria haga gracia? ¿Qué impide decir la verdad riendo?» (Alonso Asenjo / Molina Sánchez, 2006: 69).

Otro planteamiento que conjuga elementos cómicos y trágicos consiste en la doble acción, que da el protagonismo a dos personajes opuestos moralmente, a los que depara un desenlace acorde a sus conductas. La idea se expone en el «argumento» del Gastrimargus y es remachada por Abraham en las palabras finales, adoptando una estructura circular propia de la escolástica.

Aristóteles ya había reparado en algunas tragedias griegas con final feliz, si bien consideró la diversificación de la acción y la falta de desenlace trágico como signos de imperfección. Estos son precisamente los rasgos de la denominada en Italia tragedia a lieto fine. No obstante, esta modalidad dramática, difundida a través de las obras de Cinthio (Selene, Arrenopia, Eufimia, Epitia ${ }^{11}$, etc.), se sitúa hacia 1543-1572, por lo que su influencia sobre los dramaturgos españoles no fue posible hasta fechas posteriores. De hecho, la posibilidad de que la pieza de Romañá esté influida por Cinthio debilita la hipótesis de que se remonte a fechas anteriores a su representación en 1562.

Sea como fuere, Herrick (1955: 27) señaló ejemplos muy tempranos de tragicomedias humanísticas, como el Christus Redivivus (1543) de Nicholas Grimald, considerada por su autor como «tragicomedia sagrada»; y la Magdalena Evangelica (1546), a la que Petrus Philicinus denomina «comoedia tragica».

A esta tradición hispánica latina pertenece también la Tragicomedia Nabalis Carmelitidis (1557-67), de Juan Bonifacio, en la que se dramatiza el capítulo 25 de Samuel I. A juicio de Auerbach, cuya empresa teórica quedó inconclusa

10. La mezcla de géneros no se produce únicamente en las obras que reciben el título de tragicomedias. Téngase en cuenta la vaguedad terminológica que afecta al teatro escolar: «lo que un autor jesuita llamaría tragedia, otro lo llama comedia y viceversa, pues la mezcla de elementos y estructuras de comedia y tragedia es una constante desde los comienzos del teatro jesuítico a mediados del siglo Xvi en España. [...]. Pero, normalmente, se tenderá a denominar comedia a todas estas obras, aunque se las reconozca como tragicomedias» (Alonso Asenjo, 1996).

11. Según reza el desenlace del «argomento» de Epitia, por ejemplo: «Ma per lieto caso soprauenuto, fuori dell'opinione di ognuno riman contenta Epitia, \& chiede all'Imperadore gratia per Iuriste, \& l'ottiene; Et se ne rimane con lui, legata di vincolo di Matrimonio, pienamente contenta» (Cinthio 1583: sign. A3v). 
y desligada de las aportaciones más influyentes de la tradición hispánica (Rico 2011), la materia bíblica fue el principal caldo de cultivo en el que la división de estilos perdió su fundamento teórico. Según el autor, el personaje humilde «reviste necesariamente una profunda solemnidad y a menudo un carácter trágico", de manera que la "antigua regla estilística según la cual la imitación de la realidad, la descripción de episodios corrientes, sólo podía ser cómica (o en todo caso idílica) [...] se ve obligada a penetrar en las profundidades de la vida cotidiana del pueblo» (Auerbach 1993: 49). No obstante, los pastores de la Nabalis Carmelitidis no tienen una actitud solemne ni trágica. Antes bien, la etiqueta de tragicomedia parece deberse a la intervención de personajes disímiles. En extremos opuestos, están el rey David y los pastores Thyrsis, Bato y Palemón, caracteres de comedia. Por otra parte, en consonancia con el teatro escolar, se combinan las fuentes clásicas con recursos populares, como las formas poéticas tradicionales, más tarde extendidas en el teatro lopesco.

Es preciso considerar también algunas tragicomedias neolatinas de los dramaturgos jesuitas portugueses. Luís da Cruz compuso una Tragicocomoedia: Prodigvs appellata, representada en 1568; y fue autor de otra tragicomedia de tema bíblico (inspirada en el Génesis 37-50) titulada Iosephus, posiblemente representada en 1574 en Coimbra, pero no publicada hasta 1605, en Lyon ${ }^{12}$. Según pone de manifiesto Martins Melo (2004: 390-435), la obra yuxtapone actos con predominancia de la vis tragica (I-II) o de la vis comica (III-V), lo que no impide que se conjuguen recursos ${ }^{13}$.

Las ideas dramáticas de este autor se declaran en el prólogo de las Tragicae, Comicaeque Actiones (1605), que define la tragedia por la tristeza, la grandiosidad de la materia y el estilo grauior et excelsior, frente a la temática y el lenguaje popular de la comedia. En cuanto a la tragicomedia, género en el que encasilla O Prodigus, Iosephus y Manasses restitutus, se concibe como una mezcla de géneros, idea que enlaza con el Arte poética (vv. 220-50) de Horacio, quien consideró el drama satírico como una confluencia del estilo elevado de la tragedia y el humilde de la comedia, es decir, un medium dicendi genus (Martins Melo 2004: 172). Por lo demás, el autor se respalda en el consabido parlamento de Mercurio en el Anfitrión de Plauto.

Otro paratexto relevante es el prólogo en verso a la Comedia de Santa Catarina de Hernando de Ávila, redactado hacia 1596 por Cristóbal Mosquera de Figueroa. En su título, se altera conscientemente el rótulo comedia dado por su autor: Prólogo que hizo... a la famosa Tragicomedia de Sta. Catalina.

El poema comienza con una invocación a la musa trágica, Melpómene (vv. 27-9), a lo que sigue la justificación del estilo cómico: «Y a ti, Talía, que ha de ser forzoso / tomar alguna parte de tu estilo, / [...] / a usar de algunos cómicos

12. A propósito de estas representaciones, remito a Martins Melo (2004: 39 y 15, respectivamente).

13. «Continuamos a assistir a um ritmo próprio da tragicomédia: ao tom grave de Jacob, José e de Faraó, personagens de alto coturno, e a que corresponde o genus sublime, junta-se uma certa jovialidade popular para diversão do espectador» (Martins Melo, 2004: 420-1). 
discursos» (vv-31-6). León Gustá (2004: 9) ilustró la conexión de las ideas de Mosquera sobre la tragedia con la preceptiva aristotélica (temática histórica, verosimilitud, gravedad de estilo y personajes, idealización ), circunstancias que no impiden la asunción de recursos cómicos: no hay desenlace «desastrado». Ahora bien, aunque se recurra a los elementos tipificados por Aristóteles, la combinación de rasgos implica una ruptura de la separación de estilos propugnada por los preceptistas.

Las tragicomedias humanísticas ofrecen, en suma, un repertorio de propuestas dramáticas de ascendente plautino, con mezcla de personajes y registros literarios. Destaca entre estas aportaciones la de Romañá, que desarrolla una doble acción y resuelve la trama trágica con final feliz. En cuanto al plano de la preceptiva literaria, el esquema asumido en estas piezas es refrendado por autores como Pontanus en los Poeticarum Institutionum Libri Tres (1594) ${ }^{14}$.

\section{Los MOdelos italianos. Cinthio y GUARINI}

En Italia, a partir de la década de 1530, hay varios acercamientos a la tragicomedia, que tuvieron como figura sobresaliente a Giraldi Cinthio. Recordemos que, al final del capítulo 13 de la Poética, Aristóteles aludió a algunas tragedias con final feliz, que se desviaban del modelo por él descrito. Dentro de esta modalidad encaja la tragedia a lieto fine cultivada por Cinthio, quien, en el prólogo a su Altile (1543), designa tragicomedia a esta fórmula dramática en la que se castiga o recompensa a los distintos personajes en función de su conducta.

Hacia estas fechas se propició también el debate sobre la licitud de un género dramático mixto, que contaba con el precedente de la sátira en la Antigüedad clásica, en la que participan simultáneamente los personajes mitológicos y los coros de sátiros. Para el propio Cinthio, quien publicó en 1554 el Discorso intorno al comporre delle comedie e delle tragedie, el drama satírico es el germen común de la comedia y la tragedia, apreciación que entronca con el Arte poética de Horacio.

No se admiten, en cambio, influencias de la tragicomedia de Rojas. A pesar de que Cinthio conjuga la tragedia con las técnicas de otros géneros, tales como la inserción de un prólogo, rechaza la propuesta de Rojas, que considera falta de decoro (Cinzio 1973: 213).

La tradición española fue ajena a los debates de los preceptistas italianos hasta fechas tardías. Es de notar, asimismo, que hasta 1590 no se comienzan a traducir las Hecatommithi de Cinthio al español, y que sus piezas teatrales tuvieron menor repercusión que las «Novelle» (Romera Pintor, 1998: 597). Así pues, el influjo de las ideas y argumentos de Cinthio se apreciará en los

14. En palabras de Guthke (1966: 12): «combined the Plautian criterion of dramatis personae from various walks of life with the pseudo-Aristotelian one of the happy outcome to describe tragicomedy». 
dramaturgos de finales del s. Xvi y comienzos del xvir, como Juan de la Cueva y Lope de Vega ${ }^{15}$.

A partir de la década de 1580, Italia es escenario de intensos debates sobre la licitud de la tragicomedia, de los que pronto se hacen eco los espańoles. Hacia 1586, circulan versiones manuscritas de Il pastor fido, tragicomedia pastorale de Battista Guarini, que da la voz a un «messo homo, messo capra, tutto bestia», quien sorprendentemente discurre sobre materias elevadas. Unido a esto, Guarini recurre a motivos, estilos, personajes y efectos dramáticos no circunscritos a un único género, aunque procuró no distanciarse en exceso de la Poética de Aristóteles ${ }^{16}$.

Contra esta fórmula tragicómica de Guarini, se apresuró a arremeter, entre otros, Giason Denore (o De Nores), teórico de inflexible filiación aristotélica, quien no cesa en sus ataques hasta sobrevenirle la muerte en 1590, recién publicada en Venecia la edición príncipe de Il pastor fido. La edición veneciana de 1602, considerada como definitiva, es el broche de oro a más de dos décadas de disputas academicistas, pero, ¿en qué momento llegaron a España la tragicomedia de Guarini y las reflexiones de los italianos sobre la licitud del género? Con el título El Pastor Fido, la obra se publicó en español en tres ediciones de comienzos del s. XVII, a las que seguirá en 1694 una traducción de Isabel Rebeca de Correa, aparecida en Amberes y en Ámsterdam. Las primeras traducciones se imprimen en Nápoles (1602) y en Valencia (1609), y en 1622 se reproduce nuevamente en las prensas napolitanas el texto de la primera. Cristóbal Suárez, autor de la traducción de 1602, no es otro que C. Suárez de Figueroa, quien decidió depurar su trabajo en la versión valenciana de 1609, y guardó silencio ante las dos impresiones napolitanas (Martín Gaitero 1995; Arce 1999).

La obra se difundió, por tanto, en distintas versiones españolas ${ }^{17}$, a las que precede un amplio número de ediciones italianas. De esto deja constancia Gracián (1993: 566) en su Agudeza y arte de ingenio, donde se refiere a «el Guarino, en su perfecto poema de El pastor fido, impreso tantas veces y traducido en casi todas las lenguas, y en la española con propiedad y elegancia». También Cervantes dispensó elogios similares -tal vez irónicos, pero reveladores de su fama- en el Quijote de 1615.

Pero no es fácil precisar el momento en el que los españoles empezaron a leer la obra de Guarini y conocieron la polémica desencadenada en Italia, de la que ya parece hacerse eco en 1596 la Philosophía antigua poética del Pinciano (1953: III, 219-20), y más tarde otros preceptistas. En cualquier caso, es probable que las ideas sobre la tragicomedia formuladas en el Arte nuevo

15. Remito a la selección bibliográfica de Romera Pintor (1999: 371-2). Véase además la más reciente aportación de González Ramírez y Resta (2014).

16. Trambaioli (2010: 1017) destaca esta actitud en contraste con el «ademán iconoclasta» de Lope.

17. Aparte de las ediciones mencionadas, se conserva una pieza sin título y anónima, en la que se adapta casi literalmente la obra de Guarini (Rodríguez Rodríguez 1991: 215). 
reflejasen en alguna medida las innovaciones del dramaturgo italiano ${ }^{18}$. En cuanto al plano creativo, además de otras imitaciones posteriores, es conocida la temprana influencia de Guarini sobre una de las primeras piezas de Lope, $E l$ verdadero amante, fechada hacia 1588-1595 (Morley y Bruerton, 1968). Los paralelismos afectan tanto a los motivos literarios, como al planteamiento de la acción, aunque en Lope se percibe un interés por explotar «las potencialidades abiertamente cómicas inherentes a la tragicommedia» (Trambaioli 2012: 14).

\section{Conclusión}

Según se concluye del análisis de las formas tragicómicas fraguadas a lo largo del s. XVI, no existe en estas una fórmula unitaria. En algunos casos, el «placer» inicial contrasta con la «tristeza» del desenlace, o se desarrolla una doble acción, con finales que difieren; en otros, se incide en el potencial dramático derivado de las diferencias entre personajes, lo que da lugar a planteamientos diversos. Contamos con piezas en las que el progreso trágico de la acción es alterado por los efectos cómicos del habla rústica o la inserción de situaciones ridículas. Se armonizan asimismo las fuentes clásicas con recursos de tradición popular. Y hay comedias que, de acuerdo con la visión del género atribuida a Cicerón, revisten de mayor verosimilitud a los personajes y situaciones del drama, adentrándose con ello en terrenos anteriormente reservados a la tragedia.

Así pues, los elementos de la comedia y la tragedia se combinaron originando toda clase de ensayos dramáticos que se apartaron de la preceptiva clásica, si bien respetaron el decoro en lo concerniente al estilo característico de cada tipo de personaje, lo que sirvió como puente en las posteriores derivaciones de las tragicomedias hacia formulaciones cómicas o trágicas. Este examen de las modalidades tragicómicas del siglo XVI, con las que en buena parte estuvieron familiarizados los iniciadores de la comedia nueva, permite entender, según creo, algunos de los desarrollos de la fórmula lopesca, aunque este es un asunto que requeriría un estudio pormenorizado, que excede los objetivos de estas páginas.

\section{Bibliografía}

Alonso Asenjo Julio y Molina Sánchez Manuel, 2006, «Gastrimargus, tragicomedia humanística de J. Romañá / Romanyà», TeatrEsco, 1. Reed.: Romañá (2007).

Alonso Asenjo Julio, 1996, «Teoría y práctica de la tragedia en la Comedia, Tragedia o Tragicomedia de Sancta Catharina (inédita) del P. Hernando de Ávila», en Formes teatrals de la tradició medieval. Actes del VII Col.loqui de la Société Internationale

18. Remito a Trambaioli (2010), quien señala las deudas literarias y teóricas de Lope con Guarini. En opinión de la estudiosa, este fue silenciado por Lope en el Arte nuevo tal vez para resaltar su originalidad. 
pour l'Étude du Theâtre Médiéval. (Girona, juliol de 1992), Barcelona, Institut del Teatre 393-402.

Álvarez Sellers María Rosa, 1996, «Tragedia, comedia y tragicomedia desde la perceptiva dramática: para una poética de los géneros en los siglos de oro", en Mira de Amescua en candelero. Actas del Congreso Internacional sobre Mira de Amescua y el Teatro Español del Siglo XVII (Granada, 27-30 octubre de 1994), eds. A. de la Granja y J. A. Martínez Berbel, vol. 2, Granada, Universidad, 7-19.

Arata Stefano, 1988, "Una nueva tragicomedia celestinesca del s. XvI», Celestinesca, 12: $1.45-50$.

Arce Ángeles, 1999, «Las primeras traducciones castellanas de Il pastor fido: ¿Uno o dos traductores distintos?», Cuadernos de Filología Italiana, 6. 141-54.

Arellano Ignacio, 2011, «Lo trágico y lo cómico mezclado: de mezclas y mixturas en el teatro del Siglo de Oro", Rilce, 27: 1. 9-34.

Auerbach Erich, 1993, Mimesis. La representación de la realidad en la literatura occidental (1950), trad. I. Villanueva y E. Ímaz, México, FCE (2. ${ }^{a}$ reimpr.).

Barrick Mac E., 1973, ed. Gaspar Gómez de Toledo, Tercera parte de la tragicomedia de Celestina, Philadelphia, University of Pensylvania.

Blanco Mercedes, «De la tragedia a la comedia trágica», en Strosetzki (1998), 38-60.

Cabranes-Grant Leo, 1998, «La resistencia a la tragicomedia: Giraldi Cintio y una polémica sobre Celestina», Celestinesca, 22: 1. 57-66.

Cascardi Anthony J., 1976-1977, «Lope de Vega, Juan de la Cueva, Giraldi Cinthio, and Spanish Poetics», Revista Hispánica Moderna, 39: 4. 150-5.

Cinthio G. B. Giraldi, 1583, Le tragedie di m. Gio. Battista Giraldi Cinthio..., Venetia, Giulio Cesare Cagnacini [Bancroft Library, Berkeley: PQ4624 .A19 1583].

Cinzio G. Giraldi, 1973, Scritti critici, a cura di Camilo Guerrieri Crocetti, Milano, Marzorati.

Egido Aurora, 1998, «Heráclito y Demócrito. Imágenes de la mezcla tragicómica», en Strosetzki, 68-101.

Encina Juan del, 1991, Teatro completo, ed. M. Á. Pérez Priego, Madrid, Cátedra.

Esteban Martín Luis Mariano, 1987, «Huellas de La Celestina en la Tercera Celestina de Gaspar Gómez de Toledo», Celestinesca, 11: 2. 3-19.

Fernández Sebastián, 1992, Tragedia Policiana, ed. y estudio de Luis Mariano Esteban Martín, Tesis doctoral, Universidad Complutense de Madrid.

García Soriano Justo, 1945, Teatro universitario y humanístico en España, Toledo, Talleres tipográficos de don Rafael Gómez Méndez.

González Ramírez David, Resta Ilaria, 2014, «Lope de Vega, reescritor de Giraldi Cinzio: la construcción dramática de una novella de los Hecatommithi», "Deste artife». Estudios dedicados a Aldo Ruffinatto, ed. G. Carrascón y D. Capra, Alessandria, Edizioni dell'Orso, 157-171.

Gracián Baltasar, 1993, Agudeza y arte de ingenio, ed. E. Blanco, Madrid, Turner.

Guthke Karl S., 1966, Modern tragicomedy. An Investigation into the Nature of the Genre, New York, Random House.

Herrick Marvin T., Tragicomedy: Its Origin and Development in Italy, France and England, Urbana, University of Illinois Press. 
León Gustá Jorge, 2004, «El prólogo a La famosa tragicomedia de Santa Catarina de Cristóbal Mosquera de Figueroa", Salina, 18. 91-110. Reed.: en Anejos TeatrEsco, 1-38. <http://parnaseo.uv.es/Ars/TEATRESCO/textos/Catarina.pdf> [8-5-2015]

López Pinciano Alonso, 1973, Philosophia antigua poética, reimpr., ed. Alfredo Carballo Picazo, 3 vols., Madrid, CSIC.

Maguire Nancy Klein (ed.), 1987, Renaissance Tragicomedy. Explorations in Genre and Politics, New York, AMS Press.

Martín Gaitero Rafael, julio-diciembre, 1995, «El Pastor Fido. Dos versiones de Cristóbal Suárez de Figueroa: Nápoles, 1602 y Valencia, 1609», Hieronymus Complutensis, 2. 115-9.

Martins Melo António Maria, 2004, Teatro jesuitico em Portugal no século XVI: a tragicomédia "Iosephus» do P.e Luis da Cruz, S. J., Braga, Fundação Calouste Gulbenkian / Ministério da Ciência e do Ensino Superior.

Mérimée Henri, 1913, L'art dramatique à Valencia depuis les origines jusqu'au commencement $d u \mathrm{XVII}^{\mathrm{e}}$ siècle, Toulouse, Impr. et Librairie E. Privat.

Morley S. Griswold y Courtney Bruerton, 1968, Cronología de las comedias de Lope de Vega, Madrid, Gredos.

Mosquera de Figueroa Cristóbal, 2004, prólogo a La famosa tragicomedia de Santa Catarina, en León Gustá.

Muñón Sancho de, 2009, Tragicomedia de Lisandro y Roselia, ed. Rosa Navarro Durán, Madrid, Cátedra.

Newels Margarete, 1974, Los géneros dramáticos en las poéticas del Siglo de Oro: investigación preliminar al estudio de la teoría dramática en el Siglo de Oro, versiónespañola de Amadeo Solé-Leris, London, Tamesis.

Pérez de Oliva Fernán, 1976, Teatro, ed. C. George Peale, Córdoba, Real Academia de Córdoba.

Plauto, 1993, Comedias (Anfitrión, Las Báquides, Los Menecmos), ed. Benjamín García Hernández, Madrid, Akal.

Rennert M. H. Albert, 1914, ed. revisada de Farça a manera de tragedia, Valladolid, Viuda de Montero Ferrari.

Rico Francisco, 2011, «Mímesis: un libro inconcluso», Ínsula, 778. 2-6.

Rodrigo Mancho Ricardo, 1984, "Notas en torno a la Farça a manera de tragedia», en Teatros y Prácticas escénicas, Valencia, Instituto «Alfons el Magnànim», 219-41.

Rodríguez Rodríguez José Javier, 1991, «La imitación de Il pastor fido en la Comedia de Diana y Silvestro. (El valor histórico de un texto olvidado)», en Sviluppi della Drammaturgia Pastorale nell'Europa del Cinque-Seicento (Roma, 23-26 de mayo de 1990), eds. M. Chiabò y F. Doglio, Roma, Centro Studi sul Teatro Medievale e Rinascimentale, 201-34.

Rojas Fernando de, 2000, La Celestina, eds. Francisco J. Lobera y Guillermo Serés, Paloma Díaz-Mas, Carlos Mota e Íñigo Ruiz Arzálluz, y Francisco Rico, Barcelona, Crítica.

Romañá Jaime, 2007, Tragicomedia Gastrimargus, ed. Julio Alonso Asenjo y Manuel Molina Sánchez, Granada, Universidad. 
Romera Pintor Irene, 1998, «Las ediciones de la obra dramática de Giambattista Giraldi Cinzio", en El Teatro Italiano (Actas del VII Congreso Nacional de Italianistas Españoles, Valencia 21-23 de octubre de 1996), ed. Joaquín Espinosa, Valencia, Universidad, 593-600.

Romera Pintor Irene, 1999, «La obra de Giraldi Cinzio a través de sus traducciones», en Lengua y cultura: estudios en torno a la traducción: volumen II, actas de los VII Encuentros Complutenses en torno a la Traducción [24-29 de Noviembre de 1997], M. Á. Vega y R. Martín-Gaitero (eds.), Madrid, Universidad Complutense, 367-375.

Strosetzki Christoph, 1998, ed. Teatro español del siglo de oro. Teoría y práctica, Frankfurt am Main / Madrid, Vervuert / Iberoamericana.

Torres Naharro Bartolomé de, Propalladia and others works of Bartolomé de Torres Naharro, 4 vols., 1951 y 1961, ed. Joseph E. Gillet, Bryn Mawr, Pennsylvania, The Anthoensen Press.

Torres Naharro Bartolomé de, 2013, Teatro completo, ed. Julio Vélez-Sainz, Madrid, Cátedra.

Trambaioli Marcella, 2012, “Lo trágico y lo cómico mezclado” en Il pastor fido de Giovan Battista Guarini y sus reescrituras españolas», Tragique et comique liés, dans le théâtre, de l'Antiquité à nos jours (du texte à la mise en scène). Actes du colloque organisé à l'Université de Rouen en avril 2012, ed. M. Torres (ÉRIAC) et A. Ferry (CÉRÉdI)..., Université de Rouen, CÉRÉdI, «Actes de colloques et journées d'étude», n. ${ }^{\circ}$, < http://ceredi.labos.univ-rouen.fr/public/?tragique-et-comiquelies-dans-le.html>.

Trambaioli Marcella, 2010, «Lope de Vega Frente a la Tragicomedia de Giovan Battista Guarini», en Cuatrocientos años del "Arte nuevo de hacer comedias" de Lope de Vega: actas selectas del XIV Congreso de la Asociación Internacional de Teatro Español y Novohispano de los Siglos de Oro: Olmedo, 20 al 23 de julio de 2009, coord. Germán Vega García-Luengos, Héctor Urzáiz Tortajada, 2 vols., Valladolid, Universidad; Olmedo, Ayuntamiento de Olmedo, II, 1013-23.

Valdés Juan de, 2010, Diálogo de la lengua, ed. José Enrique Laplana, Barcelona, Crítica.

Vian Herrero Ana, 2003, «La Tragicomedia de Polidoro y Casandrina: relación cíclica y caminos de la parodia», en "Estaba el jardín en flor...". Homenaje a Stefano Arata, Criticón, 87: 9. 899-914.

Vicente Gil, 1996, Teatro castellano, ed. Manuel Calderón, Barcelona, Crítica. 
